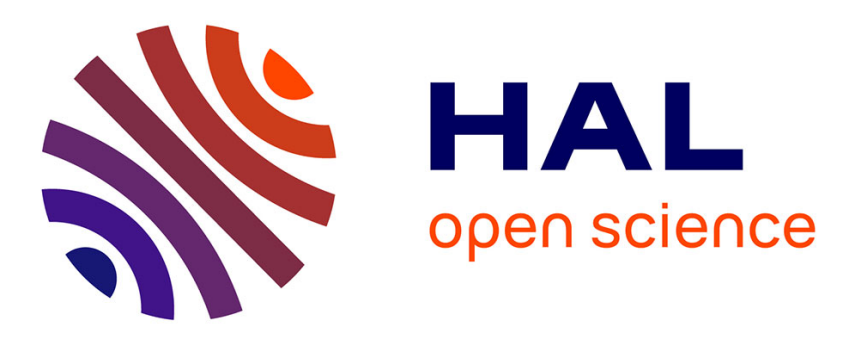

\title{
Thermal Behavior of Power Gearing Transmission, Numerical Prediction, and Influence of Design Parameters
}

\author{
Lionel Manin, Daniel Play
}

\section{- To cite this version:}

Lionel Manin, Daniel Play. Thermal Behavior of Power Gearing Transmission, Numerical Prediction, and Influence of Design Parameters. Journal of Tribology, 1999, 121 (4), pp.693-702. 10.1115/1.2834125 . hal-00797581

\section{HAL Id: hal-00797581 \\ https://hal.science/hal-00797581}

Submitted on 6 Mar 2013

HAL is a multi-disciplinary open access archive for the deposit and dissemination of scientific research documents, whether they are published or not. The documents may come from teaching and research institutions in France or abroad, or from public or private research centers.
L'archive ouverte pluridisciplinaire HAL, est destinée au dépôt et à la diffusion de documents scientifiques de niveau recherche, publiés ou non, émanant des établissements d'enseignement et de recherche français ou étrangers, des laboratoires publics ou privés. 


\section{Thermal Behavior of Power Gearing Transmission, L. Manin Numerical Prediction, and \\ D. Play \\ Professor. \\ Laboratory C.A.S.M.-I.N.S.A. de Lyon Bd. 113, 20 Av. A. Einstein, 69621 Villeurbanne, France \\ Influence of Design Parameters \\ Thermal behavior prediction of Power Gearing Transmissions during preliminary design becomes necessary in order to optimize all the parts of mechanical systems (lubrication, cooling device dimensioning, static and dynamic stress resistance, etc.). It also reduces prototype tests. The thermal network method is used to model each technological element as a thermal finite element and a nonlinear system of equations is obtained. Geometric discretization is adapted to the scale of phenomenological observation and result require- ments. As assumptions have to be made for the modeling of convection heat transfer and oil flow, experimental verifications are made. The influence of gear parameters, the effect of time varying running conditions, and oil flow defaults are then studied and discussed.}

\section{Introduction}

Computer calculations are now part of the design process. Static and dynamic mechanical behaviors of power gearing transmissions have been giving much study with numerical models (Bourdon et al., 1998). On the other hand, thermal behavior is not often taken into account in the preliminary design step. It is an old problem which has had no satisfactory solutions until now. Power gearing transmissions for automotive and aerospace applications undergo severe running conditions in terms of specific transmitted power. Temperature rises are no longer indicators for optimum design. Obviously, numerous studies (Blok, 1937; Jaeger, 1942; Ling, 1964-1973) have dealt with surface temperature increases both in dry and lubricated contacts but the definition of thermal boundary conditions remains a major problem. From a tribological point of view, the boundary conditions are defined not too far from the contact zones, as the complexity of thermal and tribological behavior in the contact is often high (Floquet et al., 1981; Kennedy, 1981; Bou-Said, 1987). Consequently, assumptions have generally been made based on the fact that thermal equilibrium will be obtained during the use of the machine. Now, such assumptions must be reinforced by general robust thermal approaches, because prototype tests have become more and more expensive and time consuming (Play, 1978). Furthermore, thermal virtual models defined during preliminary design cannot be based on hypothetical test results defined later. Thus a global thermal behavior determination of power gearing transmissions has to be carried out to calculate temperature rises based on the thermal equilibrium of all the mechanical parts of the system. Obviously, these temperature rises are not without consequences for the precisely defined geometry of parts of mechanical systems. A temperature gradient in mechanical components produces thermal expansion which can change running conditions via contact conditions and thus the behavior of the system. A thermal expansion of gearbox cases, for example, can change gear axes geometry positions, clearances, lubricant film conditions, and consequently, dissipated heat at meshing. Moreover, it is essential to know the temperature of oil lubricated systems, and the quantity of required cooling oil.

Contributed by the Tribology Division for publication in the Journal. OF TrIBoLogy. Manuscript received by the Tribology Division December 8, 1998; revised manuscript received March 23, 1999. Associate Technical Editor: M. M. Khonsari.
The prediction of thermal behavior of a power gearing transmission might be useful to evaluate cooling and lubricating conditions. Thus, it appears necessary to develop numerical models that predict the global thermal behavior of power gearing transmissions and include them in the design process. These should take into account local phenomena with a reasonable hypothesis on friction and energy losses, and it should consider all the components of the system.

Few theoretical and numerical works deal with the global thermal behavior prediction of power gearing transmissions. Most of the researches focus on one mechanical element isolated from its environment. Numerical and experimental studies (Handschuh and Kicher, 1994; Patir and Cheng, 1979; Townsend and Akin, 1981) based on finite elements analysis have analyzed meshing surface temperatures and temperature gradients in gear applications. Certain other works (Coe, 1983; Harris, 1991; Satoshi et al., 1996; Kleckner and Dyba, 1983) have been concerned with the thermal behavior of bearings using the thermal network method. Finally, some research (Changenet et al., 1996; Coe, 1989; Joule et al., 1988; Phillips, 1996) considers the whole system for thermal analysis. However, these approaches require assumptions about oil flows along the inner walls of the gearbox housing. Oil flow observations are sometimes made (Joule, 1988) and in all cases, reasonable hypotheses for oil flow definition are made for the thermal model definition.

The aim of this paper is to define a design oriented methodology for the thermal behavior prediction of a power gearing transmission, taking into account all the mechanical components. Global and local phenomena will be considered, depending on element size. The thermal network method is used in order to achieve a coherent model with reasonable computer time consumption. At the preliminary design stage, some mechanical part geometry is efficiently defined by computer while others are only schematized. On the other hand, classical finite element analysis often gives thousand of nodes and is time consuming. Consequently, thermal network models remain a good compromise at this design stage. A generic gearbox is been considered: it is composed of three shafts, three gears, six bearings, a housing, an oil lubricating circuit, and its external cooling exchanger. Experimental qualification is carried out before discussion on the influence of the elements. 


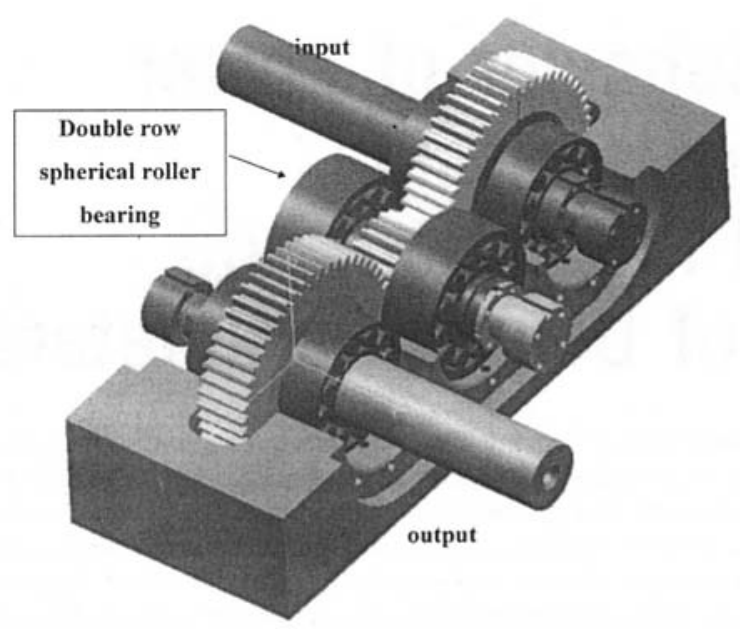

Fig. 1(a) CAD model of the generic gearbox studied

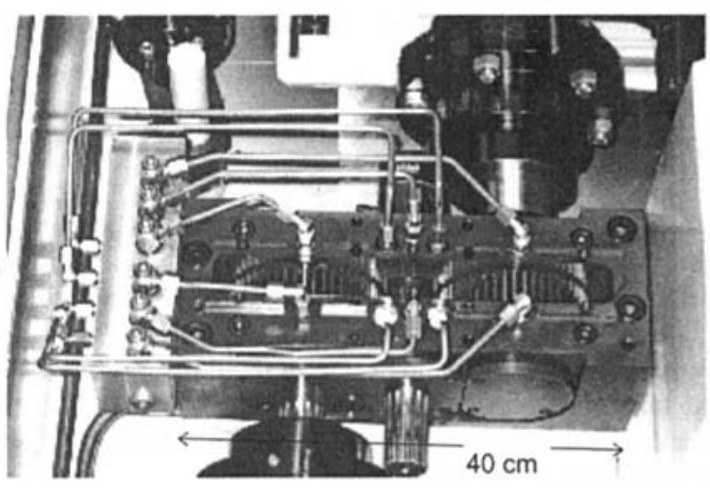

Fig. 1(b) Picture of the gearbox modeled and tested

Fig. 1 Visualization of the elements of the gearbox studled

\section{Thermal Models for Mechanical Components of Power Gearing Transmissions}

The thermal network method is used to perform numerical simulation. Energy flow is regulated by thermal conductance that constitute a net schematizing the geometry studied of both solid and liquid elements. Consequently, assumptions must be made for each element. Obviously, greater simplifications are made for fluid flows, as only common sense or rough visual observations sustain the assumptions at this stage of the preliminary design. Further, assumptions must be made for the nature of the internal gas composed of an oil-air mixture. The level of observation is thus global (geometric scale, meter). However, all technological solid elements and system architecture (Fig. 1) are considered and the model is obviously defined in three dimensions. The details of the elements are given in Appendix 1. However, local phenomena (geometric scale, $\mathrm{mm}$ or $\mu \mathrm{m}$ ) at links between mechanical components can be also taken into account. Thus, thermal nodal models have been developed for each kind of mechanical component that exists in a power gearing transmission, and each scale of observation and study.

Heat transfers by conduction, free and forced convection, mass transport and heat generation are considered, radiation is neglected due to its very low contribution in the case of classical design. Thermal conductance between the different nodes of the model corresponds to the thermal behavior of the elements. Thus a conductance matrix $[K]$ of the system is obtained. Heat dissipation by friction at contact points between mechanical parts in the meshing zone and in the bearings and also by churning loss is introduced at the corresponding nodes, giving heat input vector $\{Q\}$. As the temperature rise of the system versus running time is considered, each volume node is assigned to a specific heat parameter corresponding to the volume and material it represents. A specific heat vector $\{C p\}$ is obtained. The unknown of the problem being the vector of temperature $\{T\}$, a nonlinear system of equations has to be solved:

$$
[\mathbf{K}] *\{\mathbf{T}\}=\{\mathbf{Q}\}-\{\mathbf{C p}\} *\{\mathbf{d} \mathbf{T} / \mathbf{d t}\}
$$

The gearbox studied has no seal mounted on the shafts, however the numerical tool enables predicting the influence of the dissipated heat at the seal lip-shaft interface on the thermal equilibrium.

\section{II.1 Model Definition}

Roller Bearing Thermal Model. Only a radial gradient of temperature is assumed to exist in the rotating ring, the inner ring is thus associated with one volume node. However, the fixed ring is modeled by two volume nodes in order to distinguish the loaded from the unloaded part (Fig. A1) of the outer ring. Rolling elements are all supposed to be at the same temperature, therefore they are modeled by one volume node with a specific heat equal to the sum of the rolling elements heating contribution. Thus, bearings are modeled with ten nodes whatever their type (ball, roller, spherical etc.). The thermal links with the inner and outer ring are made by link nodes. In a general way, conduction conductance modeling the heat transfer between a node $i$ to a node $j$ can be expressed by $G_{i, j}=\lambda S_{i, j} / L_{i, j}$, where $\lambda$ is the thermal conductivity, $S_{i, j}$ is the area normal to the heat flux, $L_{i, j}$ is the distance between the nodes $i$ and $j$. Heat dissipation by friction into the bearing is modeled by the introduction of heat sources at the linking nodes of the loaded part. Convection is considered with the internal gas composed of oil and air. The corresponding thermal parameters are considered to be close to the air parameters. The calculations of heat sources and convection conductances are detailed in Appen$\operatorname{dix} 2$.

Shaft Thermal Model. Shafts in power gearing transmissions are supported by roller bearings, and shafts support gears. In order to obtain accurate heat transfer models of the shaft and the zone between the shaft and its linked mechanical components, it is

\section{Nomenclature}

\footnotetext{
$a=$ Hertz contact width, $\mathrm{m}$

$B=$ tooth width, $\mathrm{m}$

$b=\sqrt{k \rho C p}$

$C p, c_{1}=$ heat capacity, $\mathrm{J} / \mathrm{kg} / \mathrm{K}$

$d_{m}=$ mean bearing diameter, $\mathrm{mm}$

$D=$ diameter, $\mathrm{m}$

$G_{i, j}=$ thermal conductance, $\mathrm{W} /{ }^{\circ} \mathrm{C}$

$h=$ convection coefficient, $\mathrm{W} / \mathrm{m}^{2} /{ }^{\circ} \mathrm{C}$

$m=$ gear modulus, $m$

$M_{\text {friction }}=$ bearing friction torque, $\mathrm{N} \cdot \mathrm{mm}$
$M_{0}=$ viscosity dependent friction torque, $\mathrm{N} \cdot \mathrm{mm}$
$M_{1}=$ load dependent friction torque, $\mathrm{N} \cdot \mathrm{mm}$
$R_{c}=$ constriction thermal resistance, ${ }^{\circ} \mathrm{C} / \mathrm{W}$
$r=$ radius, $\mathrm{m}$
$S=$ normal surface to heat flux, $\mathrm{m}^{2}$
$T=$ temperature, ${ }^{\circ} \mathrm{C}$
$V i=$ volume associated to node $i, \mathrm{~m} 3$

$Z=$ number of teeth
}
$\mathrm{Nu}=$ Nusselt number
$\operatorname{Re}=$ Reynolds number
Pr $=$ Prandtl number
$\mathrm{Gr}=$ Grashof number
$\omega_{\text {roul }}=$ rotation speed of bearing, $r / m i n$
$\omega_{i}=$ gear rotation speed, $\mathrm{rad} / \mathrm{s}$
$\beta=$ rolling element contact angle, deg
$\lambda, k=$ thermal conductivity, $\mathrm{W} / \mathrm{m} /{ }^{\circ} \mathrm{C}$
$\nu=$ cinematic viscosity, $\mathrm{mm}^{2} / \mathrm{s}$
$\mu=$ dynamic viscosity, $\mathrm{Pa} \cdot \mathrm{s}$




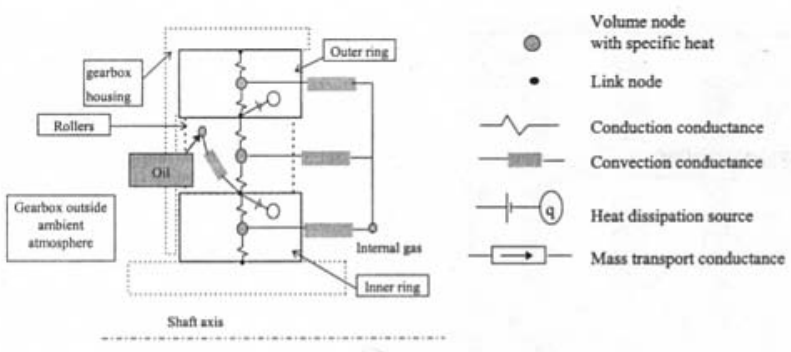

Fig. 2 Roller bearing thermal model

necessary to place a node at each link, as for a section change. Here, shafts are modeled with three volume nodes and are linked to bearings and gear by link nodes (Fig. 3). Heat transfers into the shafts are effected by conduction and are expressed with conduction conductance. Heat is dissipated from the shaft external surface by forced convection with the internal gas (oil-air mixture), and with the ambient atmosphere for the ambient outlet extremity. Mathematical expressions of these thermal exchanges are given in Appendix 2. Note that the gearbox studied has no seal mounted on the shafts. However in general cases, seal elements can be introduced and calculations can be made to predict the influence of the dissipated heat at the seal lip-shaft interface on the thermal equilibrium.

Thermal Model for Gears and Meshing Zone. Heat dissipation at the tooth surfaces is the principal heat source that causes temperature rises. As no residual oil volume stays in the bottom of the housing, churning loss is considered as nil. It appears essential to consider local thermal and mechanical phenomena in the meshing zone, in order to model the heat dissipation as accurately as possible. It was assumed that the time necessary for one gear revolution is much shorter than the time needed for any change in the bulk temperature of the gear. Therefore the temperature profile on each gear tooth can be assumed to be equal, so that the temperature gradient in the gear can be considered only along the radial direction. Thus, gears are modeled with two volume nodes, one for the bulk of the gear, and the other for the tooth and the rim if it exists (Fig. 4). Note that a more accurate model of the gear tooth can be developed with tooth slicing along the tooth width when the scale of observation is reduced. This model will be presented in the second part of this paper.

Thermal Models for Housing and Lubricating Circuit. Each power gearing transmission system has its specific housing and lubrication system, therefore it is not possible to define a general thermal model of housings. However in a general manner, a housing exchanges heat by natural convection with its internal gas and the external ambient atmosphere (forced convection if the housing is movement or an ambient atmosphere flow exists), and by forced convection with oil if there is oil flow onto the inside walls. Experimental observations of oil flow are made in the case of the gearbox studied. The oil flow obviously depends on gear rotation speed. However, oil flow mainly occurs on the A and B

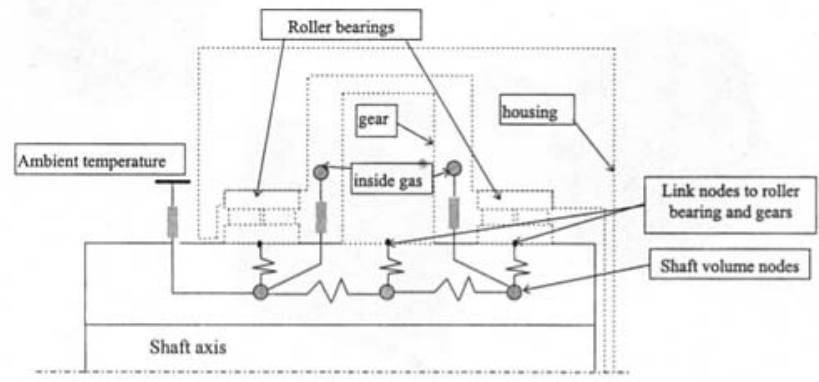

Fig. 3 Shaft thermal model

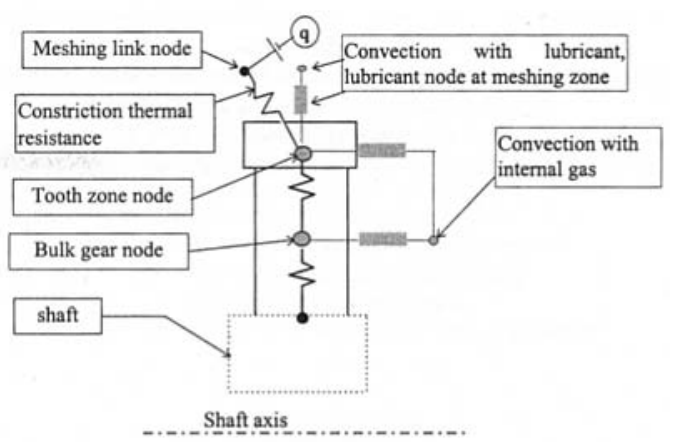

Fig. 4 Gear and meshing zone thermal model

internal walls (Fig. 5). Here also, the internal gas is an unknown air-oil mist. It is assumed that thermal parameters are close to the air parameters. The housing (Fig. 5) is modeled with 16 volume nodes and 32 link nodes modeling heat transfer with the wall and with the bearings. Convection between link nodes on the side walls and internal gas and ambient atmosphere is considered (not represented in Fig. 5(b)). The lubricant circuit is modeled with 20 volume nodes linked together by mass transport conductance and linked to the solid network by convection conductance. Note that a finite element model of the CAD geometry of the housing has been formulated for other studies, it is composed of 1832 isoparametric hexahedrons. Regarding the number of elements, it is worth using the thermal network method. The oil heat exchanger is modeled as a negative heat source depending on the oil and ambient atmosphere temperatures.

II.2 Thermal Behavior Calculation. Once all the components of the gearbox are modeled, the final thermal nodal model is obtained in order to simulate thermal behavior. The total number of nodes of this system is 148 . The resolution of the nonlinear system of equations is done by applying the Newton Raphson method. Calculations allow predicting the temperature rises of all the components of the system and the heat flux during running time. Geometrical data of the mechanical system and thermal values are defined in an input data file. The flow chart of Fig. 6 shows the different computation steps. All the convection terms of the conductance matrix $[K]$ are temperature dependent, so they are recalculated at each iteration in the Newton Raphson convergence loop (Fig. 6), likewise for the lubricant properties. The calculations stop when the simulated total running time is reached. Computation is performed with Matlab®, a simulation of running time of two hours takes $30 \mathrm{mn}$ on PC (266 Mhz).

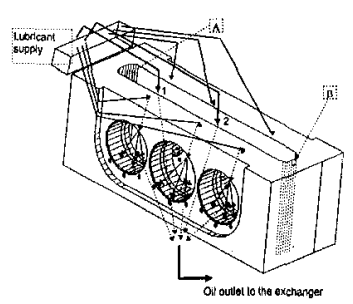

a) Definition of the housing

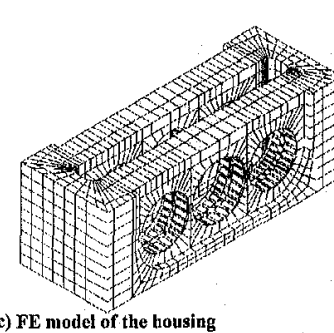

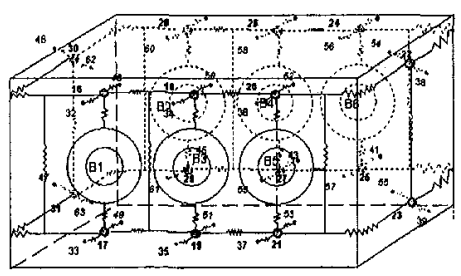

b) 3D view of the thermal network of the housing

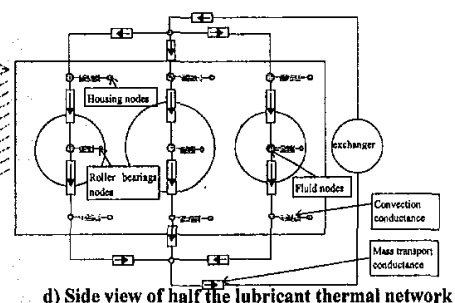

Fig. 5 Thermal model of the housing and the lubricant circuit 


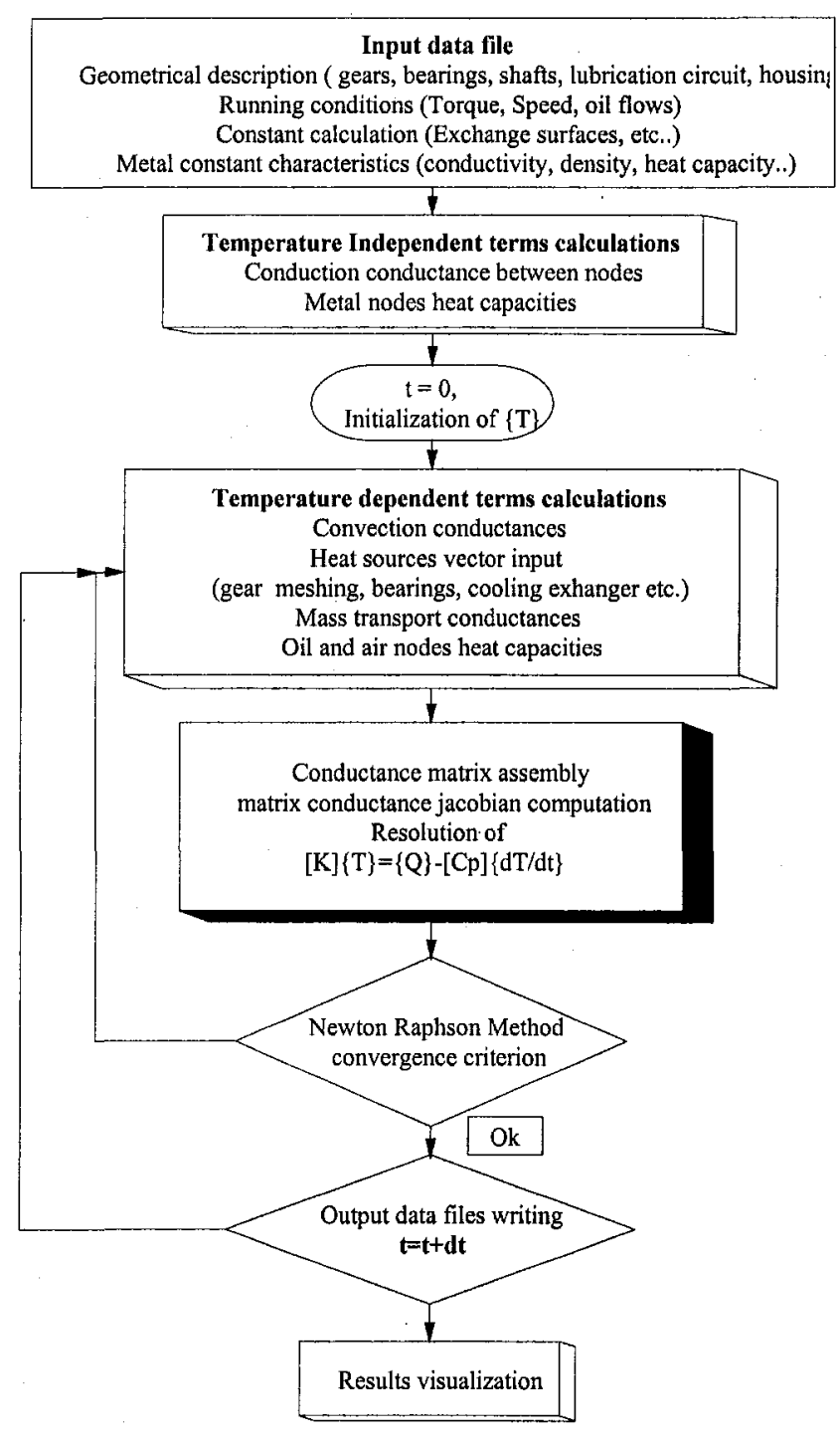

Fig. 6 Computer program flow chart

It should be noted that all the conductances are calculated according to the geometrical parameters of the components of the gearbox, therefore any change in the geometrical description is automatically taken into account in the calculation of the conductance matrix. Hence, the influence of the geometric design parameters of the different parts of the system on thermal behavior can be computed. The post processor of the computer program allows visualization of the temperature map (Fig. 7) of the power gearing transmission at any moment of the simulated running time, in the same way as for the temperature rises of the gearbox components. The temperature map represents a section view of the gearbox according to the plane defined by the gear axis; all the components are shown. The power evacuated by oil at meshing, in the bearings and in the housing is calculated, likewise with the ambient atmosphere with the wall of the housing. In Fig. 7, the following facts can be noted when the thermal steady state is obtained:

- mean tooth contact temperature is equal to $117^{\circ} \mathrm{C}$ and maximal shaft temperature is equal to $90^{\circ} \mathrm{C}$,

- a temperature gradient exists in the tooth zone of the gears, but in the bearings and in the housing the temperature is nearly the same,

- a temperature gradient of $20^{\circ} \mathrm{C}$ exists in the pinion shaft while it is lower for the wheel gear shafts,

- inner ring temperatures of the roller bearings and corresponding shaft zones temperatures are the same,

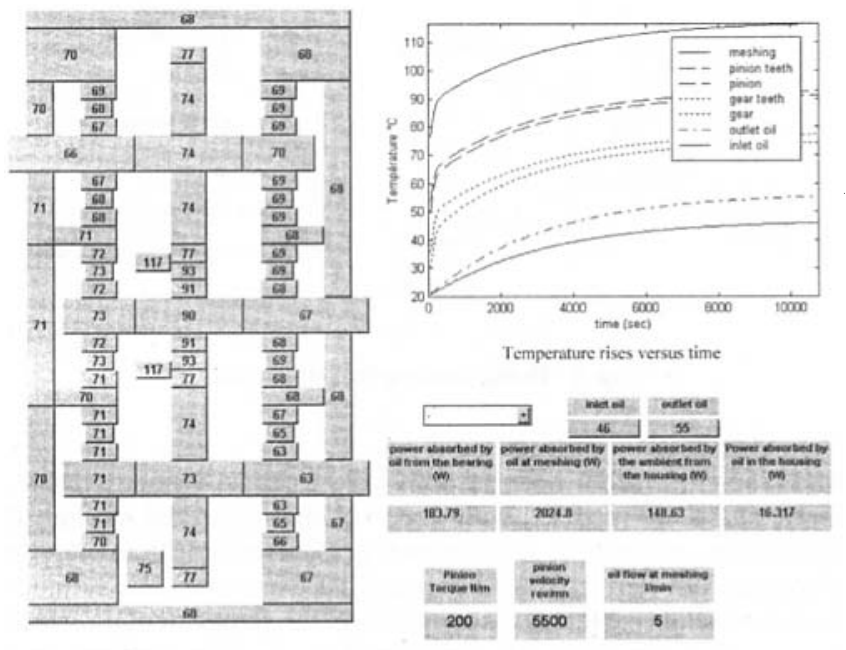

Fig. 7 Temperature map of the gearbox studied

- roller bearing temperatures correspond to the mean temperature between inner and outer rings,

- the outlet side of shafts in contact with ambient atmosphere is colder than the internal one, thus an effect of convection with external ambient atmosphere is observed,

- internal gas temperature of $75^{\circ} \mathrm{C}$ is observed and the average housing temperature is equal to $69^{\circ} \mathrm{C}$

Note that the oil flow of the lubricating circuit is generally fixed at $5 \mathrm{l} / \mathrm{min}$ for the gears and $0.3 \mathrm{l} / \mathrm{min}$ for the bearings. The steady state is reached faster for the gear and the shafts than for the housing and the bearings. 85 percent of energy loss occurs from the contact gear zones.

II.3 Experimental Results and Comparison With Numerical Results. Experimental measurements of temperatures and heat flux have been made on the transmission described in Fig. $1(b)$. The locations of thermocouples were chosen in order to be able to validate globally the model. Moreover, the number of thermocouples was limited to 8 due to the acquisition device capability. Hence three thermocouples were mounted on the wheel gear no. 1 (the slip ring can transmit 3 temperature signals), and four other on fixed parts as described below and on Fig. 8. The instrumentation defined permits qualifying globally the model for the gears, shafts and bearings likewise with the housing and lubricant circuit. Thermocouples of type $K$ and of $1 \mathrm{~mm}$ in diameter have been mounted (Fig. 8):

- in a wheel gear tooth (1), in the middle part of the wheel gear (2) and between the inner ring of a bearing and the shaft (3),

- the outer ring of the same bearing (4), inside the gearbox (5), into the housing above a bearing (6), outside the gearbox (7).

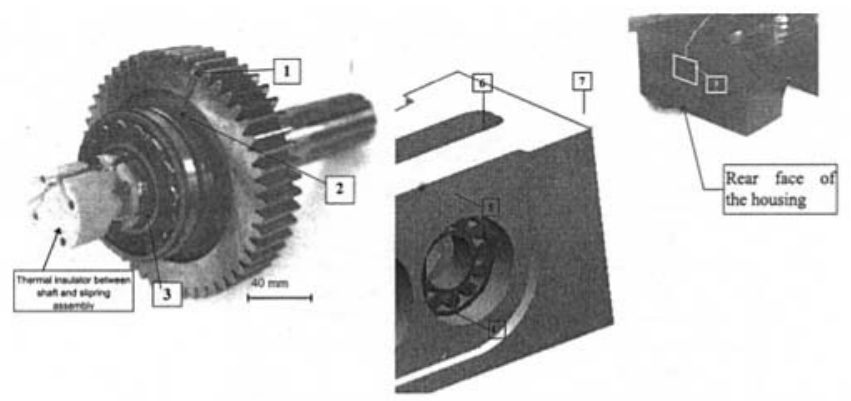

Fig. 8 Thermocouples and flux meter locations 


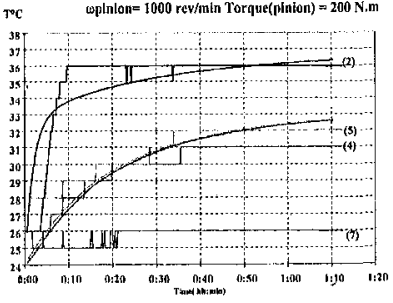

(a)

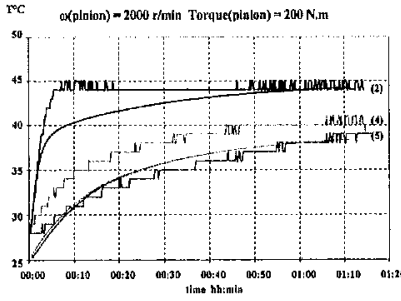

(b)
Fig. 9 Temperature rise measurements and simulation

A flux meter (8) has been also fitted on the outside wall of the gearbox housing. The mechanical characteristics of the studied gearbox are presented in Appendix 1. Temperature rises are recorded via a data acquisition board. Signals from rotating thermocouples are transferred to the computer acquisition device with a slip-ring assembly mounted on the thermal insulator coupling (Fig. 8 ). Due to acquisition device resolution the accuracy of temperature measurement is of $1^{\circ} \mathrm{C}$.

Simulated temperature rises are represented on the following figures with solid smooth curves, whereas experimental temperature rises are represented by step-by-step curves due to thermal data acquisition board accuracy. The comparison (Figs. 9 and 10) between experimental and simulated results shows a generally good agreement. However, note that for the wheel gear tooth temperature an experimental stabilization time is shorter than the numerical one. Indeed, the corresponding node of the model represents the whole bulk gear whereas the thermocouple no. 2 gives the local temperature at mid diameter of the gear. So, there is a heat capacity difference between the model node and the measurement point which corresponds to the observed difference between the numerical and recorded stabilization time. Moreover, one can notice a good concordance for the slope of the curves of temperature rises likewise with the steady-state values.

On Figs. 9 and 10(a), one time the predicted temperatures for the housing (5) and outer ring (6) (which are almost the same under low load condition) are close to the experimental temperature of the outer ring (Fig. 9(a) and Fig. 10(a)), and the other time to the housing measured temperature (Fig. $9(b)$ ). In order to explain this, it should be remembered at first that the acquisition accuracy is of $1^{\circ} \mathrm{C}$. Therefore it is not possible to say, from Figs. $9(a)$ and $9(b)$, to which experimental temperature the predicted temperatures are the closest because the difference between the measured temperatures of the housing and of the outer ring cor-

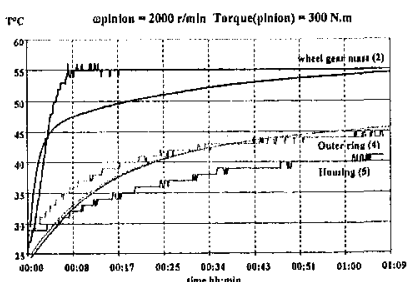

(a)

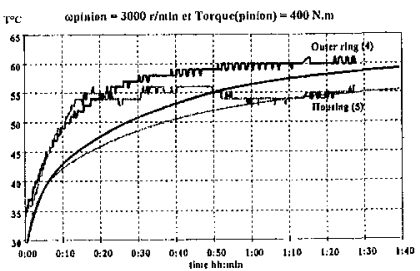

(c)

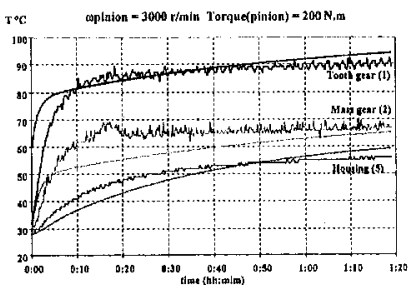

(b)

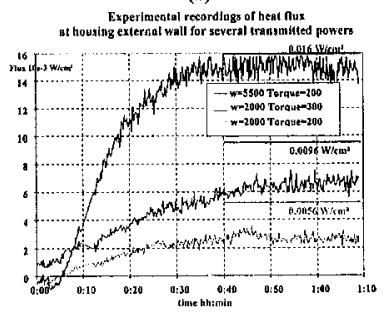

(d)
Fig. 10 Temperature rise $(a, b, c)$ and heat flux $(d)$ measurements com pared with numerical predictions responds to the accuracy. On the other hand, on Fig. 10(a) the transmitted power is higher and the measured temperature difference between is now about $5^{\circ} \mathrm{C}$. The predicted temperatures are close to the outer ring measured temperature. This may be attributed to the fact that the support of the housing is not modeled and therefore the large thermal inertia of the housing does not appear with the predicted temperatures.

Temperature of the gear wheel increases linearly with velocity and torque, and is directly linked to oil flow at meshing. Oil temperature rises with dissipated heat at meshing, i.e., with the transmitted power. The same trends are observed with the bearings. Experimental recordings of heat flux at the external wall of the housing are plotted versus time (Fig. $10(d)$ ) in comparison with numerical predictions at steady state represented by horizontal lines. From a global point of view, it can be seen on Figs. 9 and 10 that the numerical thermal equilibrium is not completely reached after $40 \mathrm{~min}$ in comparison to the experimental results. This may be attributed to the difference between the numerical boundary conditions and real test bench conditions. Here again, the fact that the housing support is not modeled may be an explanation. Moreover, the accuracy of measurement does not permit the observation of very small change in temperature, so when the steady state is nearly reached, small temperature variations are not detected. The agreement between numerical and experimental results is better for high transmitted power. The thermal steady state appears clearly with the curve shape. Experimental measurements of temperature at the different points listed above permit validation of the numerical tool for the determination of the global thermal behavior of power gearing transmissions.

\section{Numerical Simulations and Presentation of Results}

In a power gearing transmission, the sizes of the mechanical elements are defined according to resistance criteria regardless of the thermal consequences. Current trends of saving weight in mechanisms cause a reduction of the heat dissipation capacity of the power gearing transmission, so that the classical operating temperatures are increased. Cooling devices can be an alternative in design. But before defining cooling capacities, sensibility analysis for design optimization is generally made. The preceding numerical model allows the prediction of the influence of design parameters on the thermal behavior of the mechanism studied.

III.1 Influence of Gear Geometry Parameters. The design parameters of gears must be separated into two groups, as local and global geometries are involved. Tooth crowning and gear axis misalignments that govern tooth load distributions will first be considered. Then, rim thickness, web thickness and its position along the tooth width can be considered and the computation of their influences on the thermal behavior of the gear and the gearbox must be emphasized. However, a more accurate model for the teeth of the gear and the pinion (Fig. 11) has been developed

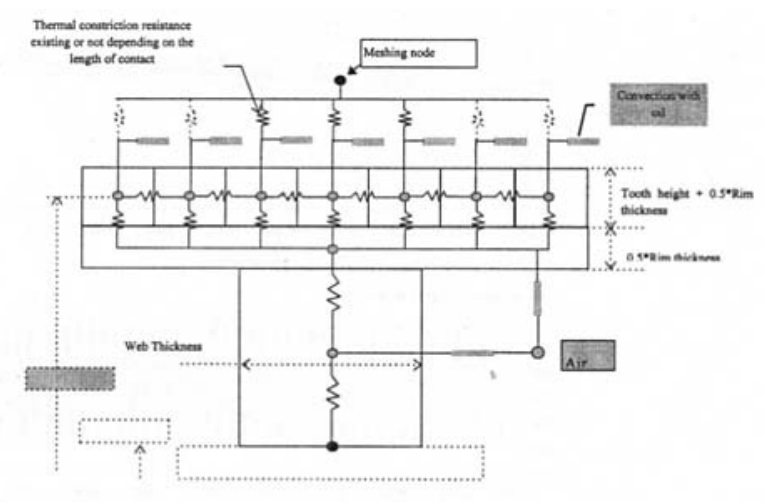

Fig. 11 Fine definition of the tooth thermal model 

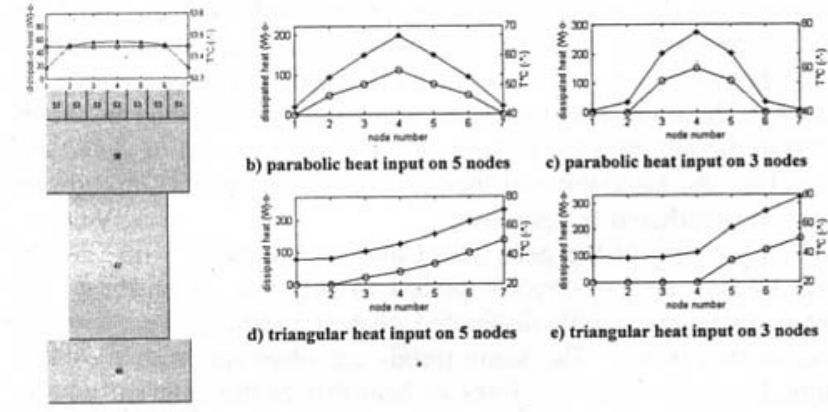

b) parabolic beat input on 5 nodes

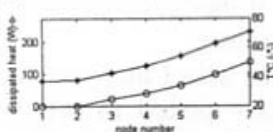

d) triangular heat input on $\mathbf{5}$ nodes

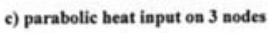

a) uniform heat input distribution

on the 7 nodes of the tooth

Fig. 12 Visualization of mean temperature dlstributions for different heat input distributions (Constant total heat entering the gear $370 \mathrm{~W}$ )

for the computation, the same model has been developed for the pinion, while the same initial model has been kept for the bulk of the gear and pinion. Nonuniform heat input along the tooth width is introduced with nonconstant constriction thermal resistance between the meshing zone node and the teeth nodes. Indeed, tooth crowning gives non-constant load distribution along the tooth width, and therefore heat generation at meshing will not be the same along the tooth width (Fig. 12, line style markers: circle).

Three different contact lengths along the tooth width modeling the heat input distribution involved by crowning were considered, but with the same total heat input. Note that the bulk temperature of the gear is not modified by the heat input distribution. However, the mean mass temperatures of the tooth (line style marker: star, Fig. 12) are governed by the heat input, and a significant temperature gradient can occur along the tooth in the case of a wide crowning. The temperature gradient caused by crowning and contact length reduction can produce circumferential tooth thermal expansion of the same order of magnitude as the tooth crowning modification. Thus, the tooth thickness is modified, as is the load distribution and therefore the frictional heat input profile. The different plots of temperature distribution along the tooth width (Fig. 12(b,c)) show that tooth temperature at the edges can be lower than the bulk temperature of the wheel; heat flux by convection through the lubricant is higher than heat flux by conduction into the gear. The two triangular heat distributions corresponding to tooth load distribution modifications due to gear axis misalignments (Figs. 12(d) and (e)) give bigger temperature gradients but the same increase of temperature $\left(40^{\circ} \mathrm{C}\right)$. Now, regarding global gear geometry effects, calculations have been performed for various rim and web thicknesses (for the web, 10.5-21-31.5 (mm), and for the rim, 7.3-14.5-21.8 (mm)). The web was placed either on the median plane, or on one side of the gear. The results show that within the domains of parameter variations, the web and rim thicknesses have no significant thermal consequences on the wheel gear temperature distribution. However, the web thickness influences the mechanical behavior, the tooth load distribution, and therefore the heat input.

III.2 Effect of Time Varying Running Conditions. Gear transmissions often transmit variable power as working conditions vary with time. Torque and angular speed can vary across a large range of amplitudes and frequencies. Consequently, temperature distributions depend on time. Obviously, thermal parameters govern the phenomenon but materials are imposed by mechanical conditions on design and the thermal parameters are considered to be fixed. With the nodal model, varying running conditions of the power gearing transmission can be computed. Indeed, if one considers a constant angular speed and a transmitted torque as a sine function $T_{\text {orque }}=A+B \sin (\omega \cdot t)$, the effect on the temperature rises of each mechanical element of the gearbox can be predicted. Figure 13 represents the computed temperature rises of the pinion, the wheel gear and the outer ring of a bearing for $T_{\text {orque }}=200+$ $100 \sin (2 \pi \cdot t / 120)$, the computed dissipated heat at meshing and in a bearing are also represented. The frequency is relatively low but a period of 120 seconds appears to be an average value of input power variation. The oscillating torque has a large influence on the mechanical parts with small masses, i.e., meshing tooth gear zone. The effect of temperature variations decreases with the increasing mass of the components and their distance from the varying heat input. For example, roller bearings reach the same temperature $\left(47^{\circ} \mathrm{C}\right)$ independently of the torque variations. Inside the gas is equal to $51^{\circ} \mathrm{C}$ for the two cases. The variations of tooth temperature and mechanical torque are in phase $\left(T \max =88^{\circ} \mathrm{C}, T\right.$ mini $=$ $79^{\circ} \mathrm{C}$ ). A decrease of torque frequency by a factor of 4 but with the same amplitude gives the same temperatures. A small decrease of the heat input in the bearing is observed due to the oil's viscosity which decreases as the temperature increases. In order to analyze the temperature fluctuations, it should be remembered that the plotted temperatures correspond to the meshing zone which is continuously cooled by the lubricant jet that evacuate most of the dissipated energy. Therefore, it is not incoherent to observe the predicted temperatures of the pinion and gear teeth zone oscillating with the"same frequency of heat input and with an amplitude of 10
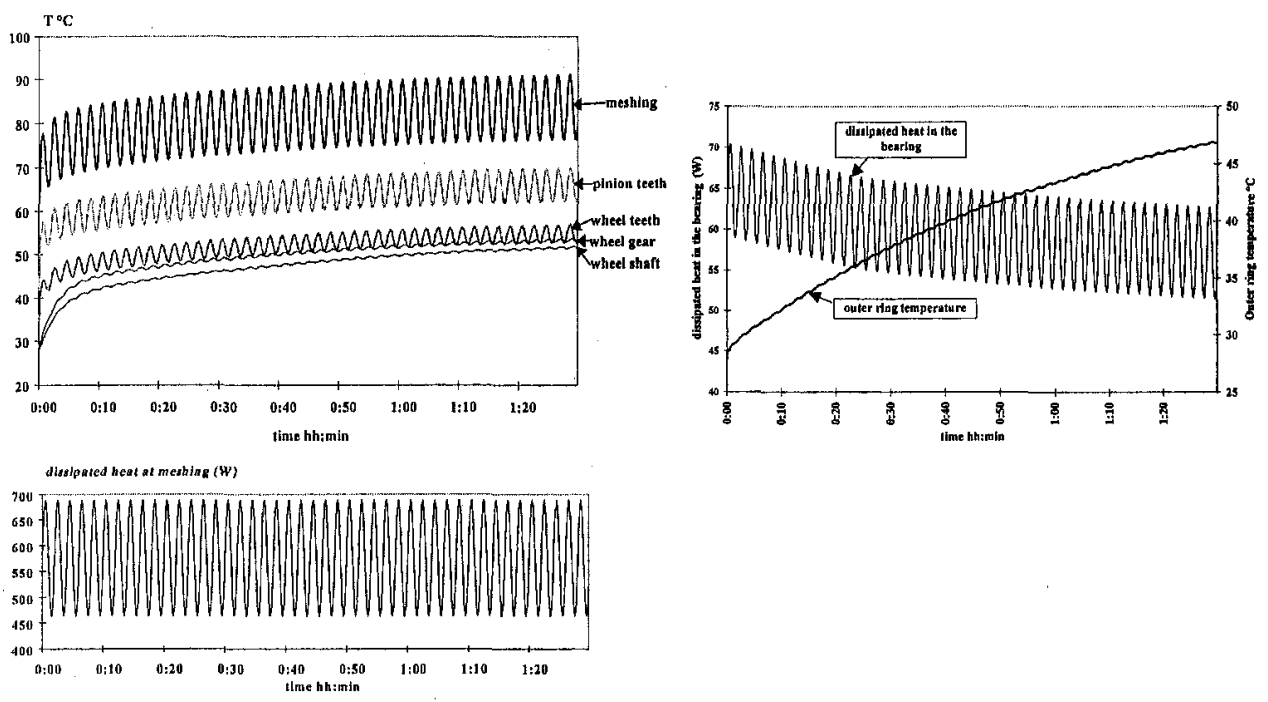

Fig. 13 Temperature rises for oscillating torque and therefore oscillating heat input 


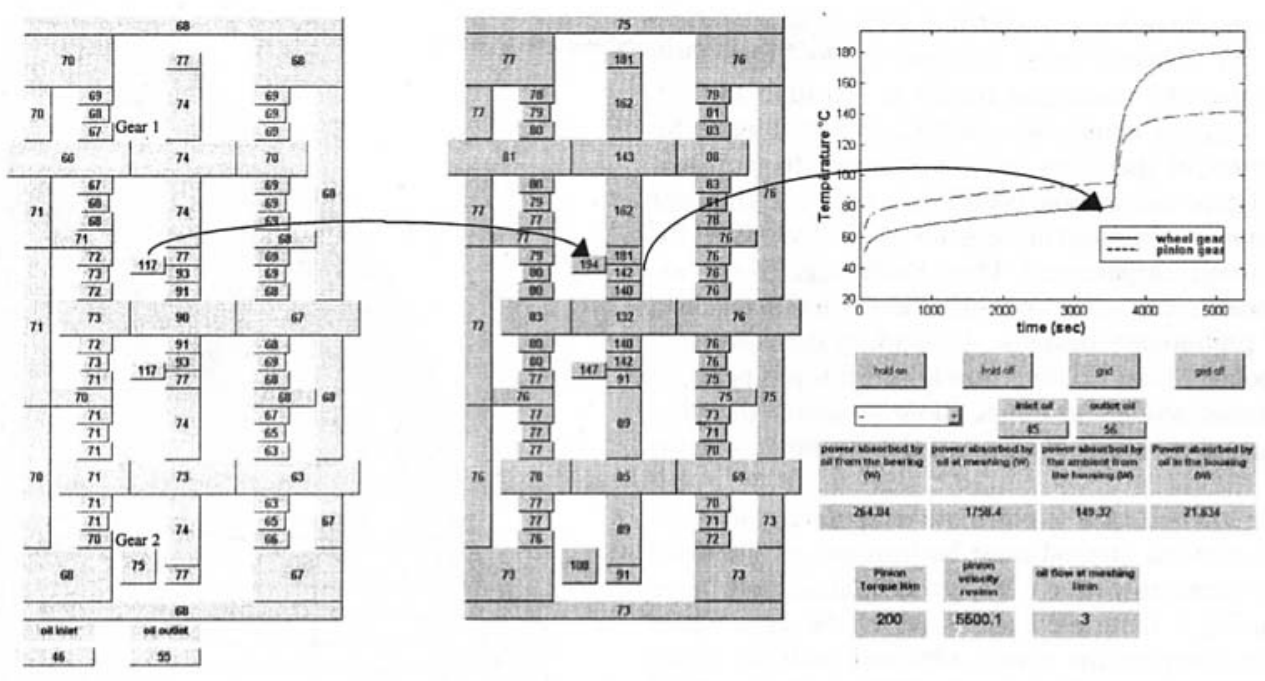

Fig. 14 Comparison of thermal maps of the gearbox without and with a lubrication defect at meshing

to $5^{\circ} \mathrm{C}$. On the other hand, the mass temperature of the gear vary very slightly.

III.3 Oil Flow Defect. The numerical tool enables predicting the thermal behavior of a power gearing transmission during operation and under transient time running conditions. Another application is to predict thermal behavior with a defect on a component of the system, such as cooling or lubrication. The gearbox studied is composed of a lubricant jet on the two meshing zones. A lubrication defect on one meshing zone has been simulated by stopping the lubricant supply after the system reaches steady state ( 2 hours). The temperature rise $\left(117^{\circ} \mathrm{C}\right.$ to $194^{\circ} \mathrm{C}$, Fig. 14) appears in the lubricant starvation zone $(30 \mathrm{~min}$ after). Note that the second oil jet gives lower mean contact temperatures in the second meshing zone $\left(147^{\circ} \mathrm{C}\right)$. For the two meshing zones the lubrication conditions are degraded due to the temperature increase. However, considering the curves of Fig. 14, the upper tooth temperatures before the oil defect were situated on the pinion, whereas after oil lubrication starvation, the upper temperatures are situated on the wheel gear. Obviously, a temperature gradient inversion gives highly transient lubrication conditions that can produce scuffing and major wear degradation. The same kind of defect was applied to a bearing and the same trends with lower amplitudes were observed. A default in the heat exchanger can also be simulated, in order to predict the remaining running time of the system before failure.

\section{Discussion: Model Sensitivity and the Limits and Advantages of the Nodal Method}

In thermal analysis, most convection heat transfer coefficients are calculated using empirical formulas. So uncertainty as to the accuracy of these coefficients may exists. In order to study the impact of poor values used for convection coefficients on the thermal calculations performed with the numerical model, several simulations were carried out considering possible variations of convection conductance. Exchange coefficients in natural convection for horizontal or vertical surfaces are well known, thus the study of their influences is of little interest. On the contrary, forced convection formulas used for gears, bearings, and shafts are not as reliable as natural convection formulas. Consequently, the impact of a change in the convection coefficients of a rotating shaft in air

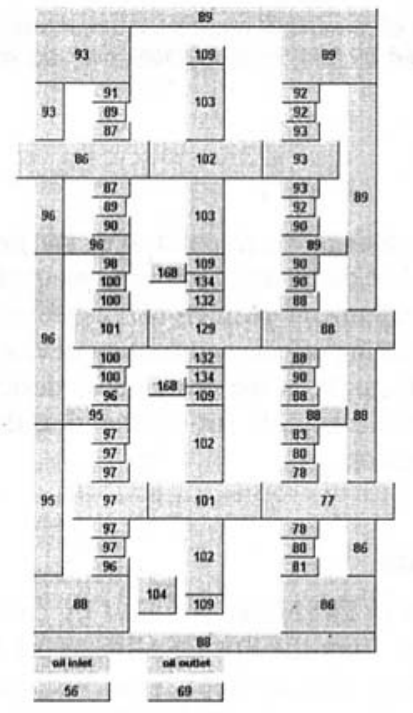

a) $2^{\star} h$ (shaft - air)

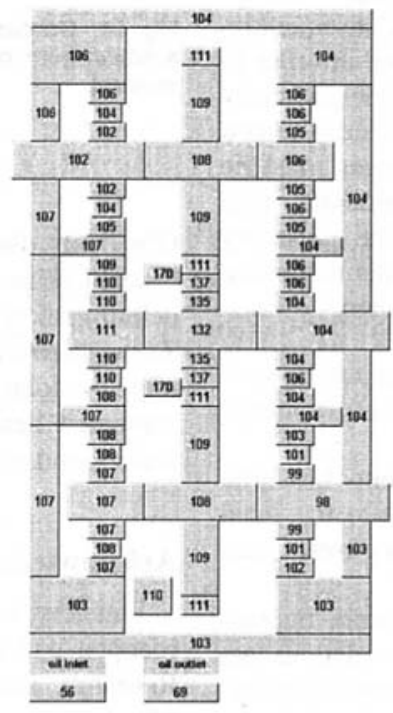

b) normal configuration

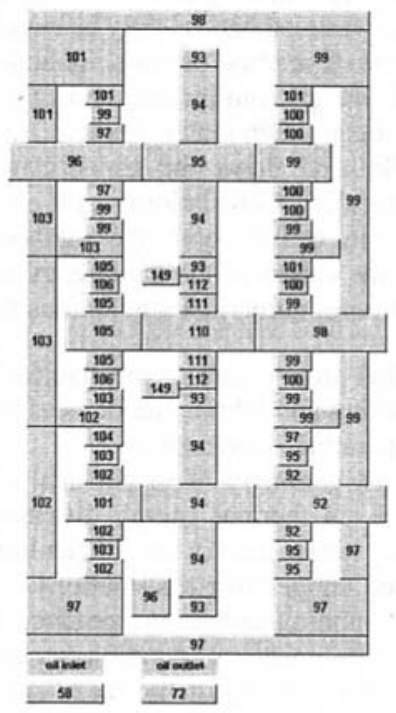

c) $2^{*} \mathrm{~h}$ (gear - oil)

Fig. 15 Effect of changes in convection coefficlent on thermal behavior prediction 
and gears in lubricant have been considered. Comparison of thermal maps (Fig. 15) obtained with changes in the convection coefficient shows that the numerical model is sensitive locally. Indeed, when the shaft-air convection coefficient is multiplied by two, the temperatures of the gears are not affected. In the same way as for the oil-gear convection coefficient, only a significant change in temperature is observed in the gears $\left(170^{\circ} \mathrm{C}\right.$ to $149^{\circ} \mathrm{C}$ for the mean contact tooth temperature). Thus, knowledge of reasonable convection coefficient values permits the definition of temperature maps of preliminary designs. As is often the case, new designs are extrapolated from existing solutions. Thus it is possible to apply such thermal models to define more precisely the convection coefficient and consequently the calculated temperature for new designs.

Returning to the method used to calculate temperature distributions, the thermal network method must be justified, as the finite element method is commonly used everywhere. Calculations have been performed using a finite element model of the gear wheel studied in order to compare the results obtained with the nodal method for the same heat input. Note that the FEM model has 4607 nodes and the thermal model has 168 nodes. The calculations were performed with nonconstant heat input along the tooth width, due to the tooth edge effect on the load distribution (Kim, H. C., et al., 1998). Figure 16 shows that only the mean surface temperatures differ slightly but mass temperatures are almost the same for the two methods. Note that boundary conditions must be well specified with the FE model. Under these conditions, thermal gradients are obtained for the tooth volume. Returning to the objective of preliminary design, it is more important to ensure global thermal equilibrium than to know specific thermal behavior. The two methods based on the same fundamental equations are complementary. Moreover, even if it stays global in nature, the thermal network method gives efficient and useful results with a fine an accurate description of the architectures of mechanical systems. The results presented on Fig. 16 corresponds to a transmitted power of $60 \mathrm{~kW}$ and a dissipated heat input entering the gear equal to $345 \mathrm{~W}$. Calculations were performed considering a higher transmitted power equal to $120 \mathrm{~kW}$, same trends were observed concerning bulk gear temperatures but a difference occurred concerning the surface temperature.

\section{Conclusion}

Thermal behavior prediction of Power Gearing Transmission is necessary during preliminary design. Some mechanical elements are well defined while others can only be suggested. Consequently, the thermal network method permits remaining global in order to ensure thermal energy equilibrium, and providing fine geometry modeling if necessary. Obviously, numerical methods are based on assumptions. Both oil flows and air cooling exchanges must be considered carefully. Calculations and experimentations were made in order to qualify both the method and the geometry modeling, and the values of the parameters used in the numerical model. Furthermore, numerical simulations have shown:

- the global architecture of mechanical systems and associated cooling and lubrication devices have a great influence on temperature distributions,

- the global geometry of mechanical components has little influence on thermal energy distribution while the local geometry parameters in the contact link zones governs heat input and temperature distributions,

- varying running conditions produce temperature fluctuations in the energy dissipation zones. The variations are smoothed depending on the mass and the distance separating the elements,

- a fault in the lubricating system gives new thermal temperature maps but can produce major changes in thermal gradients between elements.
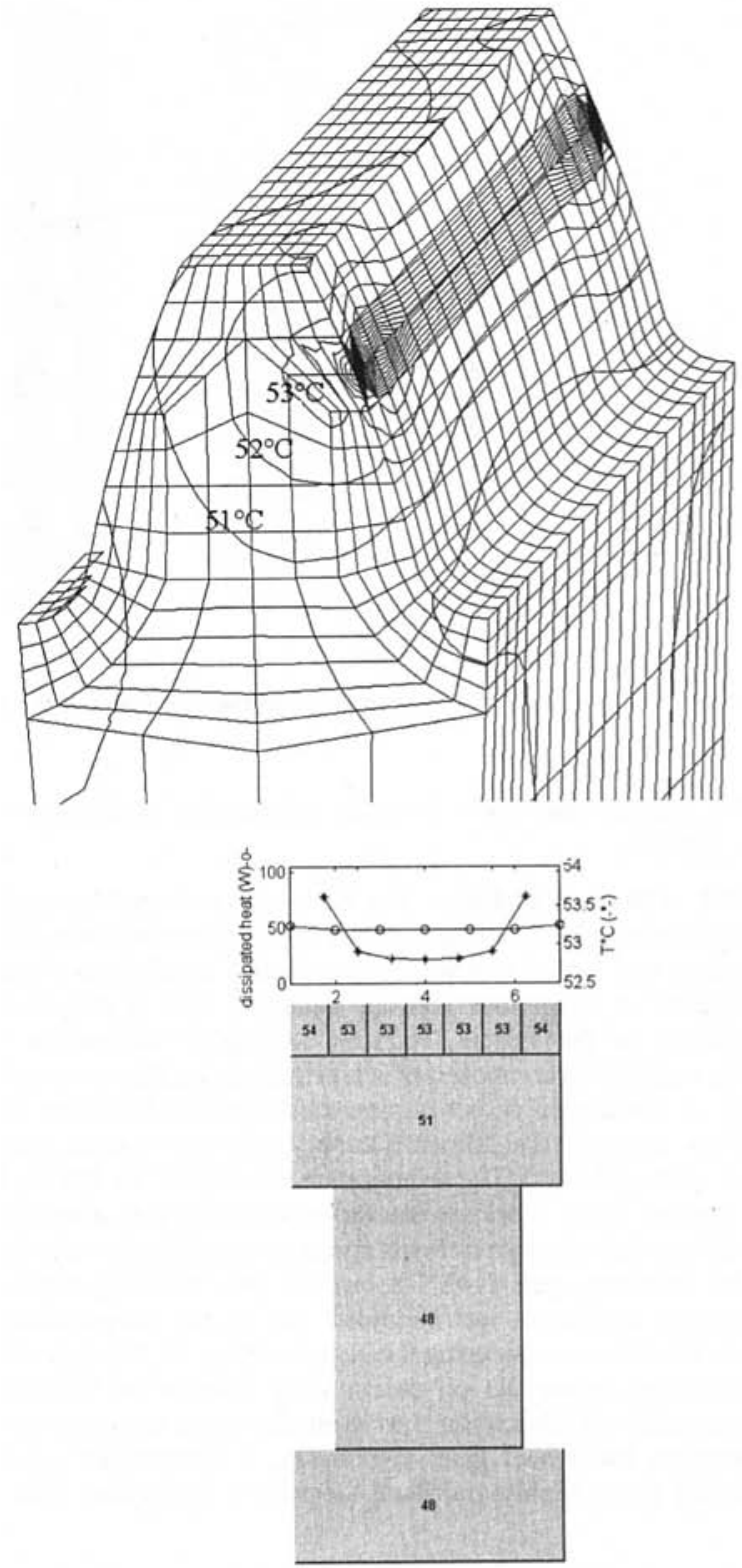

Fig. 16 Comparison of numerical results of temperature distribution in a wheel gear obtained by the finite element method and the network method

Obviously, the conclusions correspond with the general trend of thermal behaviors, but the thermal network method gives a good determination of the temperature maps of the mechanical elements. At the same time, cooling effects and cooling device dimensioning must be done satisfactorily at the preliminary design. The results presented here become a basis for further fine thermal contact studies and optimization.

\section{Acknowledgments}

Financial support to INSA was provided by contract from Eurocopter and a grant from the French Ministry of Education and Research. The authors wish to thank Mrs. Nuc, Mrs. Cazin, and Mr. Antoniotti from Eurocopter for their helpful discussions. The authors would also like to thank also P. Soleilhac, a technician in our laboratory, for his technical assistance, and J. P. de Vaujany, an assistant professor, for his help on FE analysis. 


\section{References}

Blok, H., 1937, "Theoretical Study of the Temperature Rise at Surfaces of Actual Contact under Oilness Lubricating Conditions," General Discussion on Lubrication, Proc. Inst. Mech. Engrs., Vol. 2, p. 222.

Bourdon, A., Rigal, J. F., and Play, D., 1999, "Static Rolling Bearing Models in CAD Environment for Studies of Complex Mechanisms," Part I and Part II, ASME Jouknal of Tribology, Vol. 121, Apr., pp. 205-223.

Bou-said, B., 1987, "A Global Method for Thermohydrodynamic Problems by Finite Element Method," Symposium on Thin Film Fluid, The 1987 ASME Applied Mechanics, Bioengineering, and Fluids Engineering Conference, Cincinnati, Ohio, pp. $1-6$.

Changenet, C., Denis, M., and Nast, D., 1996, "Thermal Study of Railway Reduction Gears," VDI BERICHTE NR1230, pp. 461-471.

Coe, H. H., 1983, "Predicted and Experimental Performance of Large Bore HighSpeed Ball and Roller Bearings," Nasa, Technical Report, LRC, pp. 203-221.

Coe, H. H., 1989, "Comparison of Predicted and Mcasured Temperatures of UH-60A Helicopter Transmission," NASA, Tech. Report 89-C-010, 12 pp.

Colin, F., Floquet, A., and Play, D., 1987, "Thermal Contact Simulation in 2-D and 3-D Mechanisms," ASME Journal or Lubrication Technology, Vol, 110, pp. $247-252$

Floquet, A., and Play, D., 1981, "Contact Temperature in Dry Bearings. Three Dimensional Theory and Verification," ASME JOURNAL, OF LuBRICATION TECHNOLOGY, Vol. 103, pp. 243-252.

Handschuh, R. F., and Kicher, T. P., 1994, "A Method for Thermal Analysis of Spiral Bevel Gears," Proceedings of the 1994 International Gearing Conference. Newcastle UK, pp. 347-352.

Harris, T. A., 1991, Rolling Bearing Analysis, Wilcy, New York

Jaeger, J. C., 1942, "Moving Sources of Heat and the Temperature al Sliding Contact," Proc. Roy. Soc., Vol. 56, pp. 203-224.

Joule, D., Hinduja, S., and Ashton, J. N., 1988, "Thermal Analysis of a Spur Gearbox, Part 1: Steady State Finite Element Analysis. Part 2: Transient State Finite Element Analysis of the Gearbox Casing," Proceedings of the Institution of Mechan ical Engineers, Vol. 202 C4, pp. 245-262.

Kennedy, F. E., 1981, "Surface Temperature in Sliding System, a Finite Element Analysis," ASME Journal of Lubrication Technology, Vol. 103, pp. 90-96.

Kim, H. C., De Vanjany, J. P., Guingand, M., and Play, D., 1998, "Stress Analysis of Cylindrical Webbed Spur Gears: Parametric Study," ASME Journal of Mechanical Design, Vol. 120, pp. 349-357.

Kleckner, R. J., and Dyba, G., 1983, "High Speed Spherical Roller Bearing Analysis and Comparison with Experimentat Performance," Nasa, Technical Report, pp. 239-252.

Ling, F. F., and Pu, S. L., 1964, "Probable Interface Temperatures of Solids in Sliding Contact," Wear, Vol. 7, p. 23.

Ling, F, F., 1973, Suffaces Mechanics, Wiley NY, $320 \mathrm{pp}$

Patir, N., and Cheng, H. S., 1979, "Prediction of the Bulk Temperature in Spur Gears Based on Finite Element Temperature Analysis," ASLE Transactions, Vol. 22, pp. 25--36.

Phillips, A. E, 1996, "The Development of a Practical Thermal Rating Method for Enclosed Gear Drives," AGMA, ISBN 1-55589-676-6.

Play, D., 1978, "Testing Alloys for Use in Heat Treatment Furnaces," Tribology International, June, pp. 193-196.

Satoshi, H., Susumu, M., Hiroshisa, Y., and Yasugoshi, T., 1996, "LubricationStarvation Research Test of Helicopter Transmission," Proceedings of The Power Transmission and Gearing Conference, ASME, San Diego, pp. 119-124.

Terauchi, Y., Nagamura, K., Wu, C. K., and Ikejo, K., 1996, "On the Heat Balance of Gear Equipment (on a Method for Predicting the Bulk Temperature Rise of Gears and Temperature Rise of Oil with Dip Cooling)," JSME, Series III, pp. 97-104.

Tobe, T., and Kato, M., 1974, "A Study on Flash Temperature on the Spur Gear Teeth," ASME Jownal of Engineering for Industry, pp. 78-84.

Townsend, D. P., and Akin, L. S., 1981, "Analytical and Experimental Spur Gear Tooth Temperature as Affected by Operating Variable," ASME Journal of Mechanical Design. Vol. 103, pp. 216-226.

Winter, A., and Blok, H., 1974, "Fling-off Cooling of Gear Teeth," ASME Journal of Engineering for Industry, pp. $60-70$.

\section{A P P E N D I X 1}

\section{Description of the Power Gearing Transmission Studied}

Bearings mounted on:

- the shafts supporting the wheel gear: FAG 22308ES, double row spherical roller bearing;

- the shaft supporting the pinion: FAG 22208ES, double row spherical roller bearing;

Shafts: 3 steel shafts, external diameter $40 \mathrm{~mm}$, internal diameter $15 \mathrm{~mm}$, length $210 \mathrm{~mm}$.

\begin{tabular}{cccc}
\hline & & Pinion & Wheel \\
Gears & (steel 16NC6) & 20 teeth & 51 teeth \\
\hline Pitch Modulus & Pressure Angle & Tooth width & Center distance \\
$2.57 \mathrm{~mm}$ & $20^{\circ}$ & $30 \mathrm{~mm}$ & $92.71 \mathrm{~mm}$ \\
\hline
\end{tabular}

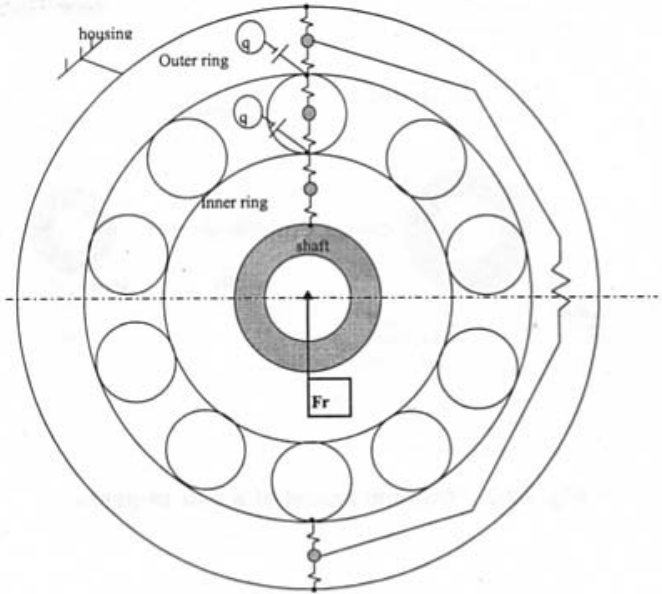

Fig. A2-1 Thermal model of a bearing

Housing (steel): length: $405 \mathrm{~mm}$, height: $150 \mathrm{~mm}$, width: 150 mm, thickness: $56 \mathrm{~mm}$

Lubricant oil: MIL 23699, Fluid flow on gear: 3-5 1/m, Fluid flow on bearings: $0.25-0.31 / \mathrm{min}$

Cooling device: Oil/air exchanger with a cooling capacity of 80 $\mathrm{kW}$ with an oil flow of $100 \mathrm{1} / \mathrm{min}$ for an oil-air temperature difference of $40^{\circ} \mathrm{C}$

Running conditions: Maximum pinion velocity angle: $6000 \mathrm{rev} /$ min, maximum pinion torque: $800 \mathrm{~N} \cdot \mathrm{m}$

\section{A P P E N D I X 2}

\section{Formula Used for Roller Bearings and Gears}

The value of the bearing heat sources is calculated (Harris, 1991) from the heat quantity $(q)$

$$
\begin{gathered}
q=\frac{1}{2} M_{\text {friction }} * \omega_{\text {ring }} \text { where } M_{\text {friction }}=M_{0}+M_{1} \\
\left\{\begin{array}{l}
M_{0}=10^{-7} f_{0}\left(v \omega_{\text {roul }}\right)^{2 / 3} d_{m}^{3} \rightarrow\left(v \omega_{\text {roul }}\right) \geq 2000 \\
M_{0}=160 * 10^{-7} f_{0} d_{m}^{3} \rightarrow\left(v \omega_{\text {roul }}\right)<2000
\end{array}\right. \text { and } \\
M_{1}=f_{1} * \mathrm{Fr}^{a} * d_{m}^{b}
\end{gathered}
$$

where $a, b, f 1$ are known coefficients depending on the bearing type and the applied load (radial, axial). Bearings exchange heat with the internal air of the gearbox. That heat transfer is modeled for the outer ring by considering the natural convection between a vertical fixed plate and air. As the inner ring is rotating, the heat transfer with internal air is made by forced convection. By considering the heat transfer between a rotary disk in air, exchange is expressed with a forced convection conductance:

$$
\begin{array}{rl}
G_{k, \text { internal_air }}=0.4 & * \lambda_{\text {air }} * \sqrt{\frac{\omega_{\text {ring }}}{\nu_{\text {air }}}} * P_{r_{\text {air }}}^{1 / 3} * S_{\text {ring }} \text { for } \\
& R_{e}\left(\frac{\omega_{\text {air }} R_{\text {riing }}^{2}}{\nu_{\text {air }}}\right) \leq 2 \cdot 10^{5} \text { (always true in our case). }
\end{array}
$$

Heat transfer of lubricating oil with the bearing is modeled by a forced convection coefficient between the inner ring and the oil (Harris, 1991):

$$
h=0.0986\left\{\frac{\omega_{\text {ring }}}{\nu}\left(1-\frac{D_{\text {rolling_element }} * \cos \beta}{d_{m}}\right)\right\}^{1 / 2} \lambda * P_{r}^{1 / 3} .
$$

The specific heat of each volume node is calculated in a general manner by $C p\left(\right.$ node $\left.\_i\right)=\rho_{i} \cdot c_{i} \cdot V_{i}$. Mathematical expressions 


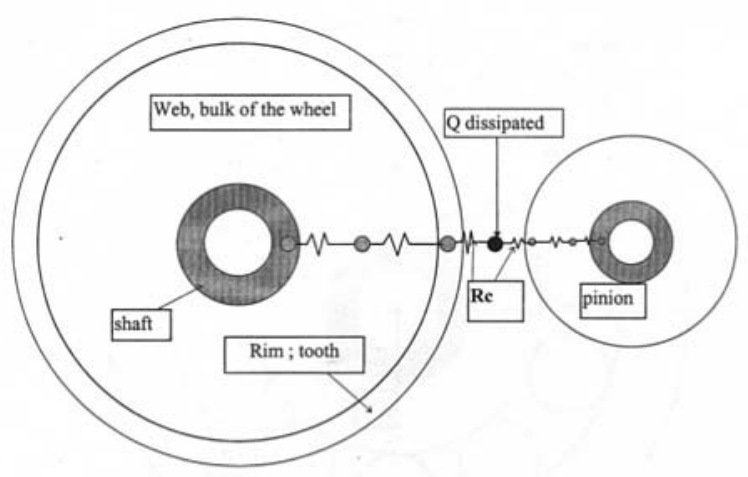

Fig. A2-2 Thermal model of a pair of gears

of the convection conductance between a rotating shaft and its surrounding air are:

$$
G_{i, \text { air }}=\frac{\lambda_{\text {air }}}{D_{\text {shaft }}} * 0.11\left[\left(0.125 \mathrm{Re}^{2}+\mathrm{Gr}\right) \operatorname{Pr}\right]^{0.35} * S_{i \text {,air }}, \quad \text { with }
$$

$\operatorname{Re}=\left(\omega_{\text {shaft }} D_{\text {shaft }}^{2}\right) / \nu_{\text {air }}, \quad \mathrm{Gr}=\left(g * D_{\text {shaft }}^{3} * \beta_{\text {air }} *\left(T_{i}-T_{\text {air }}\right)\right) / \nu_{\text {air }}^{2}$

Inside the gear heat conduction occurs and the exchange between a node $i$ and a node $j$ in the radial direction can be expressed in a general form as: $G_{i, j}=2 \pi * \lambda * B * \ln \left(r_{i} / r_{j}\right)$ with $r_{i}>r_{j}$.

The meshing zone is modeled with a link node, where a heat source $Q_{\text {gear }}$ is introduced, linked with the nodes of the wheel and the pinion by thermal contact resistance $R c$. This models the heat flux constriction due to the small hertzian area of contact between teeth. The corresponding constriction conductance can be expressed by: $G_{\text {mesh,gear }}=1 / R_{c}=(0.767 / \mathrm{J}$. $\left.B \sqrt{a} \sqrt{V r_{\text {gear }}}\right)^{-1}$. The heat source input at the meshing zone node is calculated from the formula giving the efficiency of the gear pair and the transmitted power. Gears exchange heat with internal air by forced convection and are modeled as a rotating ring. Finally, gears are lubricated by oil jet. The heat exchange between oil and gear is expressed (Winter and Blok, 1976) by a convection conductance: $G_{\text {gear, oil }}=\left(5.6 * m * b / \omega_{\text {gear }}^{1 / 2}\right) * B *$ $Z_{\text {gear }} * 2 \pi / \omega_{\text {gear }}$. 